Palavras chave: Semente germinada Potencial osmótico Estrutura celular

Histórico: Recebido 27/10/201 I Aceito 15/1 1/2015

Keywords: Germinated seed Osmotic potential

Cell structure

Correspondência: amandabiounifal@yahoo.com.br
Amanda Cristiane Rodrigues', Amauri Alves de Alvarenga', Diego Egídio Ribeiro', Renato Mendes Guimarães', Eduardo Alves', Jessé Marques da Silva Junior'

\section{REINDUÇÃO DA TOLERÂNCIA À DESSECAÇÃO EM SEMENTES DE Bauhinia forficata LINK (FABACEAE)}

RESUMO: Bauhinia forficata Link é uma espécie arbórea de interesse medicinal e agronômico. Devido à importância da espécie objetivou-se avaliar características da germinação de $B$. forficata, bem como a capacidade desta espécie em manter a tolerância à dessecação após a germinação. Os resultados indicam $B$. forficata como uma espécie com capacidade de reindução de tolerância à dessecação. Através de eletromicrografias de varredura foi possível entender os efeitos positivos de uma secagem lenta em sementes germinadas. Conclui-se então que $B$. forficata possui capacidade de re-indução de tolerancia à dessecação com até $4 \mathrm{~mm}$ de comprimento de radícula, quando tratada com solução de PEG à - I,4MPa.

\section{REINDUCTION OF DESICCATION TOLERANCE IN SEEDS OF Bauhinia forficata LINK (FABACEAE).}

ABSTRACT: Bauhinia forficata is a tree with medicinal and agronomic interest. Due to the importance of the species, the work aimed to evaluate some characteristics of germination of $B$. forficata and estimate its capacity to maintain the desiccation tolerance after the germination. The results indicate that $B$. forficata is a species with capacity to reinduction of the desiccation tolerance. The scanning electron micrographs show the benefits of slow drying in germinated seeds. In conclusion, $B$. forficata is a species with capacity to reinduction to desiccation tolerance until $4 \mathrm{~mm}$ of radicle, when subjected to treatment using PEG - I,4MPa. 


\section{INTRODUÇÃO}

A água, como fator fundamental da sobrevivência de tecidos vivos, participa dos eventos metabólicos relacionados à manutenção da viabilidade de sementes. Em relação a água, sementes ortodoxas possuem capacidade de tolerância à dessecação. Esta capacidade de tolerância a dessecação indica que o tecido poderá sofrer dessecação e manter seus tecidos vivos mesmo após a perda de 80 a $90 \%$ da água protoplásmica (HOEKSTRA et al., 200I).

Durante o processo de germinação, sementes ortodoxas perdem gradualmente a tolerância à dessecação. Quando ocorre a protusão radicular, a nova plântula é sensível à dessecação, e pode sofrer danos irreversíveis em caso de escassez de água. A radícula é a primeira estrutura do vegetal a perder a tolerância à dessecação, o que ocorre logo após a sua protrusão (BUITINKet al., 2003).

Bauhinia forficata, conhecida popularmente como pata de vaca e pertencente à família Fabaceae Caesalpiniaceae, produz sementes classificadas como tolerantes à dessecação (MEDEIROS; EIRA, 2006). Apesar de seu interesse medicinal e importância, já comprovados cientificamente (CUNHA et al., 2010), os estudos das características das sementes desta espécie são limitados. O que se sabe é que a produção de sementes é baixa, os índices de predação e imaturidade são altos, e trata-se de uma espécie ameaçada de extinção no bioma Caatinga (SILVA et al., 2003).

Assim, visando aprofundar o conhecimento sobre as sementes de $B$. forficata e entender melhor os fatores que governam os processos de tolerância à dessecação objetivou-se com este trabalho estabelecer protocolos de reindução de tolerância à dessecação em sementes germinadas de B. forficata, assim como determinar aspectos estruturais e bioquímicos que estejam relacionados com o processo de perda de tolerância após a germinação.

\section{MATERIAL E MÉTODOS}

Coleta: As sementes de B. forficata foram coletadas de indivíduos no cerrado de Boa Esperança, localizada no sul de Minas Gerais ( $21^{\circ} 05^{\prime} \mathrm{S}$ e $\left.45^{\circ} 35^{\prime} \mathrm{O}\right)$. Após a coleta, procedeu-se $\circ$ beneficiamento manual, descartando-se as sementes predadas. As sementes viáveis foram mantidas sob temperatura ambiente até atingir $20 \%$ de teor de água.
Curva de embebição e secagem: foram utilizadas quatro repetições de 10 sementes cada, mecanicamente escarificadas. Durante as primeiras sete horas, as sementes foram pesadas de hora em hora, e as subsequentes pesagens foram feitas de oito em oito horas, até 100 horas. Após esse período o material foi transferido para placas de Petri contendo solução de PEG a - I,4 MPa para controlar a perda de água em ambiente com potencial hídrico conhecido. As sementes foram retiradas da solução, secas superficialmente com papel toalha, e pesadas em intervalos de 24 em 24 horas, até 72 horas. Após esse período as sementes foram trasnferidas para recipientes contendo sílica a $20 \%$ de umidade. A umidade da sílica foi controlada utilizando-se um termohigrometro da ICEL $®$ HT208, e as pesagens foram feitas até o material retornar a $20 \%$ de umidade inicial.

Reindução da tolerância à dessecação: Para os testes de germinação foram utilizadas as seguintes condições: placa de Petri com dupla camada de papel Germitest ${ }^{\circledR}$ umidecido com $4 \mathrm{~mL}$ de $\mathrm{H}_{2} \mathrm{O}$ destilada, mantidas em câmara de germinação do tipo Mangesdorf, a aproximadamente $30( \pm 2)^{\circ} \mathrm{C}$ e luz constante. As sementes foram desinfestadas de acordo com Souza (2009). Após a protrusão radicular, foram selecionadas sementes germinadas com radículas de I, 2, 3 e $4 \mathrm{~mm}$ de comprimento, medidas com o auxilio de um paquímetro. As sementes com os comprimentos de radícula selecionados foram ditribuidas em quatro tratamentos de secagem. Para o tratamento I, quatro repetições de 20 sementes de cada comprimento radicular foram submetidas à dessecação em sílica gel ( $20 \%$ de umidade) conforme metodologia descrita por Faria et al. (2005). O grau de umidade das sementes foi monitorado utilizandose de pesagens em balança analítica até que as sementes apresentassem $20 \%$ de teor de água. Os tratamentos 2, 3 e 4 consistiram de pré-incubação em soluções de PEG 6000 à -I,4; -I,7 e -2,0 MPa, com quatro repetições de 20 sementes cada. Após 72 horas de pré-incubação nas soluções, as sementes germinadas foram submetidas à secagem em sílica, conforme descrição acima, até atingirem $20 \%$ de teor de água. Após a secagem, as sementes foram postas em condições ótimas de germinação para verificar a retomada do crescimento e desenvolvimento das plântulas. As sementes germinadas que reassumiram - crescimento da radícula foram consideradas tolerantes à dessecação, segundo descrição de Buitink et al. (2003). Nesse experimento também foram 
contabilizadas as sementes com morte da raiz primária e posterior desenvolvimento de raízes adventícias.

Composição química: Foram utilizadas sementes germinadas, sem tegumento, com radículas de comprimentos de 2, 3 e $4 \mathrm{~mm}$ de comprimento. O teor de amido das sementes foi determinado segundo o método descrito por McCready et al. (1950). Os açúcares totais extraídos pelo método de Lane-Enyon (AOAC, 1990) e determinados por Nelson (1944); e a fração protéica foi determinada pelo método de micro-Kjeldahl (AOAC, 1990). Os lipídeos foram quantificados pela metodologia descrita na AOAC (1990).

Microscopia Eletrônica de Varredura: neste ponto foram utilizadas sementes não germinadas, germinadas, germinadas com posterior secagem em sílica, germinadas e incubadas em PEG - I,4MPa por 72h, e germinadas, incubadas em PEG - I,4MPa por $72 \mathrm{~h}$ e posteriormente secas em sílica. Os tratamentos descritos foram fixados em solução Karnovsky, criofraturados $\mathrm{I} \mathrm{mm}$ do ápice radicular, lavados em tampão cacodilato, pós-fixados em tetróxido de ósmio a $1 \%$, desidratados em gradientes progressivos de acetona, levados ao aparelho de ponto crítico (Bal-Tec), metalizados em evaporador de ouro (BalTec) e observados em microscópio de varredura modelo LEO Evo40 XVP. Para cada tratamento foram utilizadas 5 sementes.

\section{Reindução da tolerância à dessecação combinada} com ABA: foram testadas três concentrações de $A B A$ ( I, 10 e $100 \mathrm{mM})$, em conjunto com PEG - I,4 MPa. Como controle foi utilizada solução de PEG - I,4 MPa. Todo o protocolo seguiu os mesmos passos citados no item anterior. Foram utilizados nesse teste 4 repetições de 20 sementes cada.

Análise estatística: ○ Delineamento Inteiramente Casualizado (DIC) foi utilizado para os testes de germinação e secagem. Os dados obtidos em cada teste foram submetidos à análise de variância (ANAVA), sendo as médias dos dados de reindução de tolerância à dessecação comparados pelo teste de Skott Knott, e os referentes a composição química comparados pelo teste de Tukey, ambos a 5\% de significância. Todas as análises foram realizadas utilizando-se o programa estatístico SISVAR (Ferreira, 1999).

\section{RESULTADOS E DISCUSSÃO}

Na Figura I estão representados os resultados referentes à percentagem de sobrevivência da raiz primária. As sementes germinadas com até $3 \mathrm{~mm}$ de comprimento, secas diretamente em sílica, apresentaram retomada de crescimento da raiz primária em baixas proporções (menos de $20 \%$ em sementes germinadas com $3 \mathrm{~mm}$ de radícula). Em relação aos métodos de secagem empregados, ○ PEG a $-1,4 \mathrm{MPa}$ foi $\circ$ que apresentou resultados mais promissores.

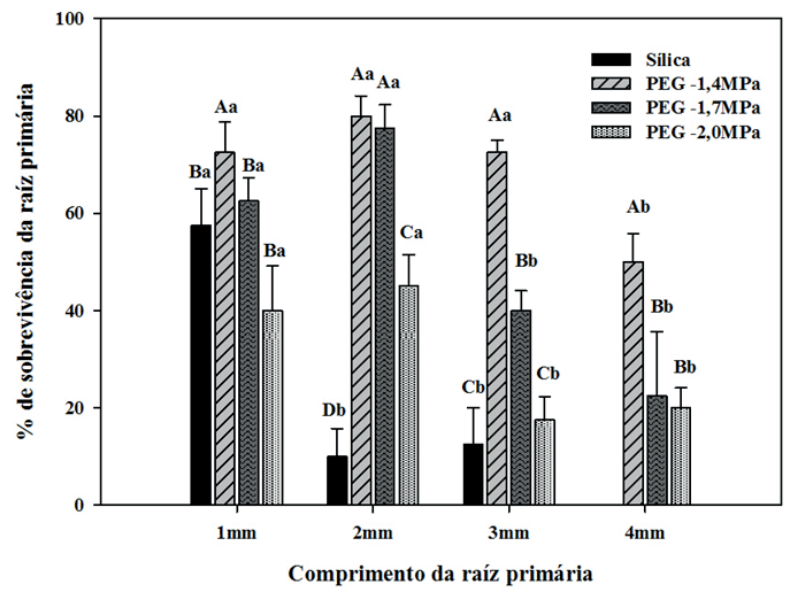

FIGURA I Porcentagem de sobrevivência da raiz primária de $B$. forficata com reindução de tolerância à dessecação após secagem em sílica, e pré-secagem em PEG - I,4 MPa, PEG - I,7 MPa e PEG -2,0 MPa. As letras maiúsculas comparam as metodologias de secagem e as minúsculas os tamanhos das radículas dentro de cada tipo de secagem. As barras indicam o erro padrão das médias.

FIGURE I Percentage of survival of the primary root in $B$. forficata considering reinduction of desiccation tolerance after dried in silica, and pre-dried in PEG - I.4 MPa, PEG - I.7 MPa and PEG -2.0 MPa. Uppercases represent the drying methods and lowercases the size of roots. The bars indicate the standard error of the averages.

Sementes germinadas tendem a perder a tolerância à dessecação, e caso o processo de germinação ocorra em condições ambientais adversas, tal como períodos de seca, as plântulas caminham para um processo de morte do meristema radicular (HONG; ELLIS, 1992; BUITINK et al., 2003). Entretanto, já foi obtido sucesso no reestabelecimento da tolerância à dessecação em sementes germinadas, em espécies como Tabebuia impetiginosa (VIEIRA et al., 2010) e Medicago trunculata (BUITINK et al., 2003; FARIA et al., 2005).

Quanto mais negativo for o potencial osmótico da solução, mais rápida será a perda de água na radícula. Se a secagem ocorrer de forma lenta e sob condições 
ideais, as possibilidades de ocorrer a retomada do desenvolvimento sem danos a radícula são maiores. A secagem lenta também propicia maior homogeneidade na perda de água, proporcionando um tempo adequado e necessário para que ocorra nas sementes germinadas a síntese de novo de moléculas e substâncias que atuam na proteção dos tecidos durante a secagem (VIEIRA et al., $2010)$. As espécies que mantém a tolerância à dessecação após a germinação até determinado comprimento radicular (no presente trabalho $4 \mathrm{~mm}$ ), têm característica de adaptação ao estresse (DAWS et al., 2007). Guimarães e colaboradores (20II) demonstraram a incapacidade de reindução de tolerância à dessecação em sementes ortodoxas de Peltoforum dubium, o que indica que esta característica de reindução à tolerância é intrínseca a algumas espécies que podem ser caracterizadas como mais resistentes a ambientes com excassez de água.

$\mathrm{Na}$ Figura 2, estão apresentados os dados de retomada do crescimento da raiz primária e morte da raiz primária com aparecimento de raízes adventícias. A raiz adventícia foi visualizada apenas quando as sementes foram secas diretamente em sílica, sem prévia incubação em PEG. A condição de reeindução de tolerância a dessecação só é considerada quando a raiz primária mantém sua viabilidade. Mas o aparecimento de raízes secundádias indica que a espécie em questão, mesmo quando em condições de secagem rápida, como a que ocorre na sílica, é capaz de retomar o processo de desenvolvimento da plântula. Apesar do foco do presente trabalho ser a reindução de tolerância a dessecação, o fato da espécie manter o crescimento mesmo após a morte da raiz primária confirma seu alto grau de tolerância à dessecação, tonando a espécie em questão um interessante modelo para futuros estudos.

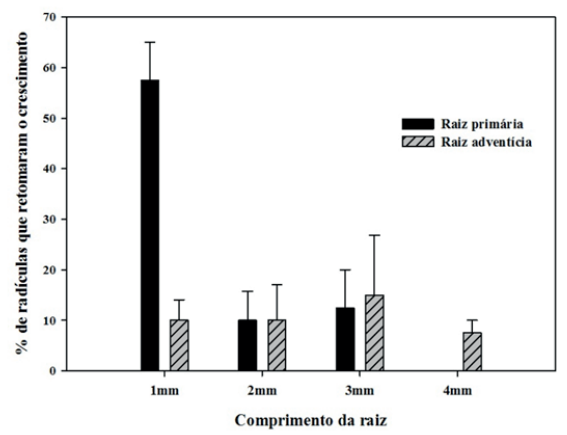

FIGURA 2 Percentagem de radículas de $B$. forficata que retomaram o crescimento da raiz primária e com desenvolvimento de raiz adventícia após a secagem direta em sílica. Barras indicam o erro padrão das médias.

FIGURE 2 Percentage of germinated seeds of B. forficata which resumption the growth of primary root and developed adventitious root after drying in silica. Bars indicate the standard error of the averages.
Pela curva de secagem (Figura 3) é possível observar como ocorre a embebição em água e a secagem em PEG -I,4 MPa, com posterior secagem em sílica. Durante as 72 horas de incubação em PEG -I,4 MPa, houve perda de aproximadamente $15 \%$ do conteúdo de água. Na secagem em sílica observou-se perda de $35 \%$ de água em aproximadamente o mesmo período de 72 horas.

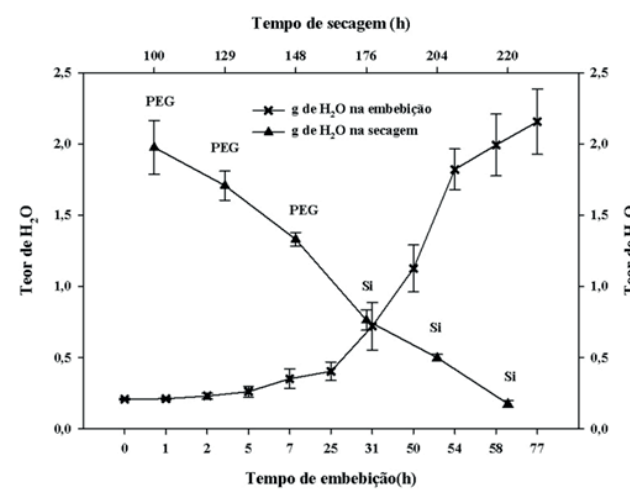

FIGURA 3 Curva de embebição e secagem de B. forficata. As barras indicam o erro padrão das médias. PEGpolietilenoglicol; Si- sílica.

FIGURE 3 Imbibition and drying curve of B. forficata. The bars indicate the standard error of the averages. PEGpolyethyleneglycol, Si-silica.

A secagem em sílica leva à diminuição do conteúdo de água de forma rápida, conforme observado na curva de secagem. Essa perda, em um curto período, pode acarretar danos nas funções celulares, e impedir a síntese de compostos que atuem na preservação dos tecidos. Esses danos, quando causados no sistema radicular, podem alterar a absorção de água e nutrientes. Já a secagem em PEG retira a água de forma lenta e em baixas quantidades, possibilitando mudanças na bioquímica da semente que podem atuar na porcentagem de sobrevivência da espécie.

$\mathrm{Na}$ Tabela I estão representados as quantidades de proteínas, lipídeos, açúcares e amido das sementes germinadas de $B$. forficata. Não foi possível observar nenhum padrão que possa ser correlacionado com a tolerancia à dessecação da espécie em questão. Com excessão dos lipídeos, as outras moléculas estudadas não apresentaram padrão linear. Organismos com capacidade de tolerância à dessecação apresentam mecanismos regulatórios na composição química que podem conferir maior tolerância à secagem, como por exemplo a presença de açucares e proteínas que interagem com a membrana plasmática e evitam sua desestruturação durante o processo de desidratação. Além disso, alguns estudos têm gerado entendimento acerca da regulação negativa do metabolismo, a presença de compostos anfífílicos nas membranas e a imobilização do citoplasma gerando uma matriz estável multicomposta (HOEKSTRAet al, 200I). 
TABELA I Teores de proteínas, lipídeos, amido e açúcares totais em sementes germinadas com 2, 3 e $4 \mathrm{~mm}$ de comprimento de radícula. Os compostos orgânicos estão expressos em $\mathrm{g} / \mathrm{l} 00 \mathrm{~g}$ de massa seca, e a estatística refere-se as colunas.

TABLE I Levels of proteins, lipids, starch and sugar in germinated seeds with 2,3 and $4 \mathrm{~mm}$ length of radicle. Organic compounds are expressed in $\mathrm{g} / \mathrm{I} 00$ $\mathrm{g}$ dry weight, and statistics refer to the columns.

\begin{tabular}{ccccc}
\hline Comprimento & Proteína & Lipídeo & Amido & Açúcar Total \\
\hline $2 \mathrm{~mm}$ & $22,8^{\mathrm{c}}$ & $8,9^{\mathrm{b}}$ & $7,9^{\mathrm{ab}}$ & 4, I $^{\mathrm{ab}}$ \\
$3 \mathrm{~mm}$ & $27,3^{\mathrm{a}}$ & $8,7^{\mathrm{b}}$ & $8,2^{\mathrm{a}}$ & $3,8^{\mathrm{b}}$ \\
$4 \mathrm{~mm}$ & $24,2^{\mathrm{b}}$ & $9,6^{\mathrm{a}}$ & $6,6^{\mathrm{b}}$ & $4,3^{\mathrm{a}}$ \\
\hline
\end{tabular}

$\mathrm{Na}$ Figura 4 encontram-se as eletromicrografias eletrônicas de varredura do ápice do embrião de sementes de $B$. forficata. Sementes não germinadas e sem embebição representam $\circ$ controle (4A). Nesta figura podem ser observados grãos de amido e depressões que poderiam estar ocupadas anteriormente por grãos de amido. Durante a criofratura, esses grãos podem ter se deslocado deixando um espaço vazio, representado pelos espaços escuros na figura. Observa-se também que o conteúdo citoplasmático e a membrana plasmática encontram-se bem estruturados, bem como as paredes celulares. Na Figura $4 \mathrm{~B}$ a seta indica o conteúdo citoplasmático após a embebição, mostrando que a parede celular está bem estruturada. Na Figura 4C é possível observar que algumas células apresentam - conteúdo citoplasmático retraído, porém com a manutenção da forma da parede celular.

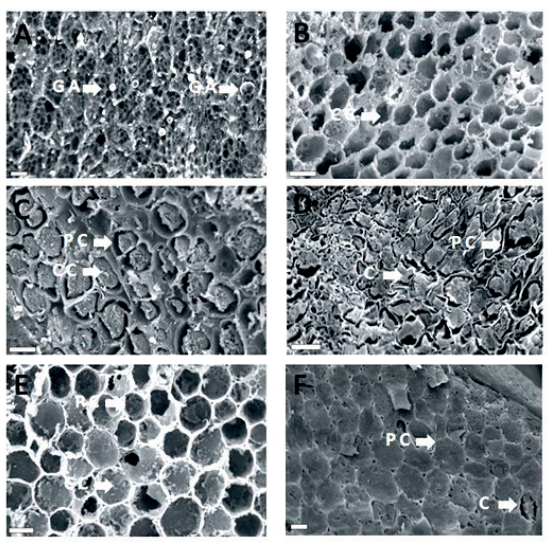

FíGURA 4 Eletromicrografias de varredura do ápice radicular de $B$. forficata. A- antes da germinação; B e C- após a germinação D- após secagem direta em sílica até $20 \%$ de umidade; E- após incubação em PEG - I,4 MPa; Fincubação em PEG - I,4 MPa com posterior secagem. PC- parede celular; CC- conteúdo citoplasmático; GAgrãos de amido; C- colapso celular. Barras $=10 \mu \mathrm{m}$.

FIGURE 4 Scanning Electron Micrographs of the root apex of $B$. forficata. A-before germination; B,C- after germination; $D$ - after drying directly in silica; $E$ - after incubation in PEG - I.4 MPa; F- incubation in PEG - I.4 MPa with further drying. PC-cell wall; CC-cytoplasmic content; GA-starch grains; C-cell collapse. Bars $=10 \mathrm{~mm}$.
Na Figura 4D o conteúdo celular encontra-se retraído e a parede celular apresenta-se desuniforme. Todas as radículas analisadas após secagem direta em sílica (4D) apresentavam o conteúdo celular retraído. Após a incubação em PEG - I,4 MPa (Figura 4E), as células assumem uma conformação parecida com as células das sementes germinadas. Após a secagem em sílica, precedida de incubação em PEG - I,4 MPa (Figura 4F), a conformação das células também se encontra próxima a de uma semente não germinada, porém, sem a presença de grãos de amido, ou depressões que indiquem que os mesmos estavam presentes na estrutura da radícula. A manutenção da integridade das membranas e paredes celulares durante a dessecação é essencial para garantir a subsequente e ordenada reestruturação celular durante a embebição e retomada do crescimento e desenvolvimento vegetal (SUN, 2002), além de contribuir para minimizar as perdas de solutos durante a reestruturação da membrana plasmática.

$\mathrm{Na}$ Figura 5, observa-se a influência de diferentes concentrações de ABA juntamente com PEG - I,4 MPa durante a reindução de tolerância a dessecação. Para as três concentrações testadas, observou-se decréscimo significativo na percentagem de radículas que retomaram o crescimento após a secagem. Não foi observado um padrão linear nas diferentes concentrações de $A B A$, sendo que a concentração de $10 \mathrm{~m}$ foi a que apresentou os menores valores.

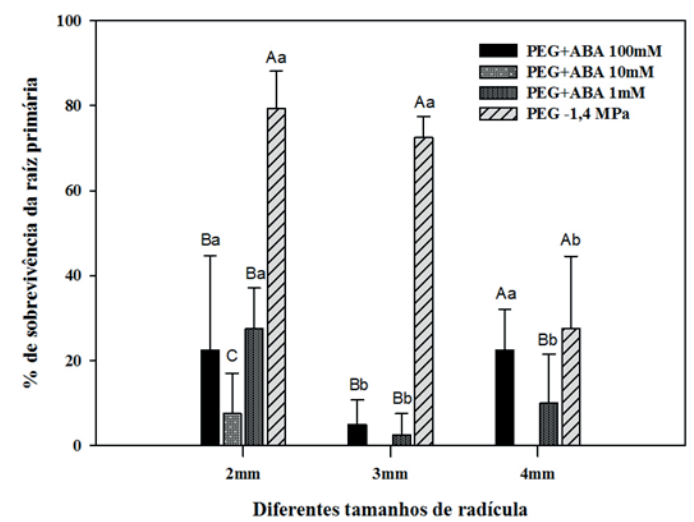

FIGURA 5 Porcentagem de sobrevivência da raiz primária em função de diferentes soluções (PEG -I,4MPa + ABAI00mM; PEG - I,4MPa + ABAIOmM; PEG - I,4MPa + ABAImM; PEG -I,4MPa) na reindução de tolerância à dessecação. As letras maiúsculas comparam os tratamentos, e as minúsculas os tamanhos das radículas. As barras indicam o erro padrão entre as médias.

FIGURE 5 Percentage of survival of the primary root in different solutions (PEG - I.4 MPa + ABAI00 $\mu \mathrm{M}$, PEG - I.4 MPa + ABAIO $\mu$ M, PEG -I.4 MPa+ ABAI $\mu$ M, PEG -I.4 $\mathrm{MPa}$ ) in reinduction of desiccation tolerance. Uppercases compare treatments and lowercases compare the size of roots. The bars indicate the standard error between means. 
Martins (2009) reporta que durante a incubação de sementes de T. impetiginosa em PEG ocorre a síntese de $\mathrm{ABA}$, fitormônio relacionado com a ativação de vários mecanismos protetores contra a dessecação, dentre eles, o relaxamento da membrana celular, que aumenta a possibilidade de redução do volume citoplasmático sem a ocorrência de danos ultraestruturais (CREELMAN; MULLET, 1991). Sreedhar et al. (2002) constatou que os embriões somáticos de Medicago sativa somente se mostraram tolerantes à dessecação e mantiveram a membrana celular íntegra quando tratados com ABA. Quando se utiliza ABA exógeno, as respostas podem diferenciar de acordo com a espécie estudada (VIEIRA et al., 20I0).

\section{CONCLUSÕES}

Conclui-se então que as sementes de $B$. forficata toleram a dessecação após a germinação com até $4 \mathrm{~mm}$ de comprimento, porém essa tolerancia dependenderá de tratamentos, sendo a solução de PEG à - I,4MPa a mais indicada entre as testadas no presente trabalho. Não se recomenda a secagem em ambientes contendo silica, visto a baixa sobrevivência. As eletromicrografias são um bom indicador de como a estrutura pode influenciar na tolerância à dessecação. As analíses de proteínas, lipídeos, açúcares e amido não mostram padrões suficientes para inferências sobre a tolerância a dessecação, bem como o uso de ABA que foi ineficiente para reindução de tolerância a dessecação.

\section{REFERÊNCIAS BIBLIOGRÁFICAS}

ASSOCIATION OF OFFICIAL AGRICULTURAL CHEMISTS. Official methods of the Association of the Agricultural Chemists. 15. ed. Washington, 1990. 1094 p.

BUITINK, J.; VU, B. L.; SATOUR, P.; LEPRINCE, O. The reestablishment of desiccation tolerance in germinated radicles of Medicago truncatula Gaertn seeds. Seed Science Research, Wallingford, v. I3, n. 4, p. 273-286, Apr. 2003.

CREELMAN, R. A.; MULLET, J. E. Abscisic acid accumulates at positive, turgor potential in excised soybean seedling growing zones. Plant Physiology, Washington, v. 95, n. 4, p. 1209-1213, Aug. 1991.

CUNHA, A. M. da; MENON, S.; MENON, R.; COUTO, A. G.; BÜRGER, C.; BIAVATTI, M. W. Hypoglycemic activity of dried extracts of Bauhinia forficata Link.
Phytomedicine, Muenchen, v. I7, p. 37-4I, Jan. 2010.

DAWS, M. I.; BOLTON, S.; BURSLEM, D. F. R. P. Loss of desiccation tolerance during germination in neo-tropical pioneer seeds: implications for seed mortality and germination characteristics. Seed Science Research, Wellington, v. I7, n. 4, p. 273-28I, Dec. 2007.

FARIA, J. M. R.; BUITINK, J.; LAMMEREN, A. A. M. van; HILHORST, H. W. M. Changes in DNA and microtubules during loss and reestablishment of desiccation tolerance in germinating Medicagotruncatula seeds. Journal of Experimental Botany, Oxford, v. 56, n. 418, p. 21।92130 , Aug. 2005.

FERREIRA, D. F. Sisvar 4.3.1999. Disponível em: <http:// www.dex.ufla.br/ danielff/softwares.htm>. Acesso em: 01 fev. 2010

GUIMARÃES, C.C.; FARIA, J.M.R; OLIVEIRA, J.M.; SILVA, E.A.A da. Avaliação da perda da tolerância à dessecação e da quantidade de DNA nuclear em sementes de Peltophorum dubium (SPRENG.) TAUBERT durante e após a germinação. Revista Brasileira de Sementes, vol. $33, n^{\circ} 2$, p. $207-215,201$ I.

HOEKSTRA, F. A.; GOLOVINA, E. A.; BUITINK, J. Mechanisms of plant desiccation tolerance. Trends in Plant Science, Oxford, v. 6, n. 9, p. 43I-438, Sept. 2001.

HONG, T. D.; ELLIS, R. H. The survival of germinating orthodox seeds after desiccation and hermetic storage. Journal of Experimental Botany, Oxford, v. 43, n. 247, p. 239247, Feb. 1992

MARTINS, J. R. Estudos ecofisiológicos da germinação e da reindução da tolerância à dessecação em plântulas de ipê-roxo. 2009. 99 p. Tese (Doutorado em Fisiologia Vegetal) - Universidade Federal de Lavras, Lavras.

MCCREADY, R. M.; GUGGOLZ, A.; SILVEIRA, V.; OWENS, H. S. Determination of starch and amylase in vegetables: application to peas. Analytical Chemistry, Washington, v. 22, n. 9, p. I I56-I I58, Sept. 1950.

MEDEIROS, A. C. de S.; EIRA, M. T. S. da. Comportamento fisiológico, secagem e armazenamento de sementes florestais nativas. Colombo: Embrapa Florestas, 2006. I 3 p. (Circular Técnica, 127).

NELSON, N. A. A photometric adaptation of Somogy method for the determination of glucose. Journal of Biological Chemistry, Baltimore, v. I35, n. 2, p. I36- I 75, May 1944.

SILVA, G. M. da C.; SILVA, H.; CAVALCANTI, M. L. F.; MARTINS, P. de L. Autecologia Bauhínia forficata L. Espécie ameaçada de extinção no ecossistema da Caatinga. Revista de Biologia e Ciência da Terra, Paraíba, v. 3, n. 2, p. I-15, 2003. 
SOUZA, E. S. Desenvolvimento de sementes e crescimento inicial de Vernonanthura phosphorica (Vell) H. Rob. 2009. 88 p. Dissertação (Mestrado em Fisiologia Vegetal) - Universidade Federal de Lavras, Lavras.

SREEDHAR, L.; WOLKERS, W. F.; HOEKSTRA, F. A.; BEWLEY, J. D. In vivo characterization of the effects of abscisic acid and drying protocols associated with the acquisition of desiccation tolerance in alfalfa (Medicago sativa L.) somatic embryos. Annals of Botany, London, v. 89, n. 4, p. 39I-400, 2002.
SUN, W. Q. Desiccation sensitivity of recalcitrant seeds and germinated orthodox seeds: can germinated orthodox seeds serve as a model system for studies of recalcitrant seeds. In: IUFRO SEED SYMPOSIUM, I., 1998, Kuala Lumpur. Proceedings. Kuala Lumpur: FRIM, 1999. p. 29-42.

VIEIRA, C.V.; SILVA, E.A.A. da; ALVARENGA, A.A.; CASTRO, E.M; TOOROP, P.E. Stress-associated factors increase after desiccation of germinated seeds of Tabebuia impetiginosa Mart. Plant Growth Regulation, n. 62, p. 257-263, 2010. 
